\title{
Análise de Controle de Vibrações, em Estruturas de Dois Andares, Através da Utilização de um Amortecedor de Massa Ativa (AMD)
}

\author{
Danielli Duó * \\ Acadêmica do Curso de Engenharia Civil, UNIPAMPA- Campus Alegrete \\ 97546-550, Alegrete, RS \\ E-mail: danielli_duo@hotmail.com \\ Jorge L.P. Felix \\ Universidade Federal do Pampa- Orientador do Grupo de Pesquisa de Mecânica Aplicada \\ 97546-550, Campus Alegrete, RS \\ E-mail: jorge.felix@unipampa.edu.br
}

\begin{abstract}
RESUMO
Os sistemas de controle têm sido uma das principais soluções, para a problemática gerada em torno de vibrações em estruturas. Isto devido a evidente eficiência encontrada em tais dispositivos. Os três principais sistemas de controle são os sistemas passivos, ativos e semiativos. O primeiro provoca a absorção de parte da energia de vibração. $\mathrm{O}$ segundo faz diferentes adaptações às formas de carregamento das vibrações de uma estrutura, além de conseguir controlar a mesma. Já o terceiro é uma mistura entre os sistemas anteriores de forma simultânea. As utilidades dos dispositivos como Amortecedor de Massa Ativa e o Amortecedor de Massa Sintonizado, são respectivamente, o desenvolvimento para introduzir um atuador ativo e a utilização do primeiro como controlador.

Este trabalho tem por objetivo o estudo das respostas de estruturas de dois andares sujeitas a vibrações induzidas em sua base por forças harmônicas ou frequências variáveis ou transientes e como também a efetividade do Amortecedor de Massa Ativa posicionada no topo da estrutura. Para este fim, um sistema de equações diferenciais de segunda ordem ajudaria a explicação qualitativa de certos fenômenos presentes no comportamento dinâmico da estrutura.

A base para a investigação deste projeto ocorre através da aplicação de um Amortecedor de Massa Ativa (AMD) em uma estrutura de dois andares, ação verificada na Fig. 1, onde a estrutura possui um AMD em seu topo atuando como forma de controle estrutural e possui uma excitação em sua base, determinada pela mesa vibratória.
\end{abstract}




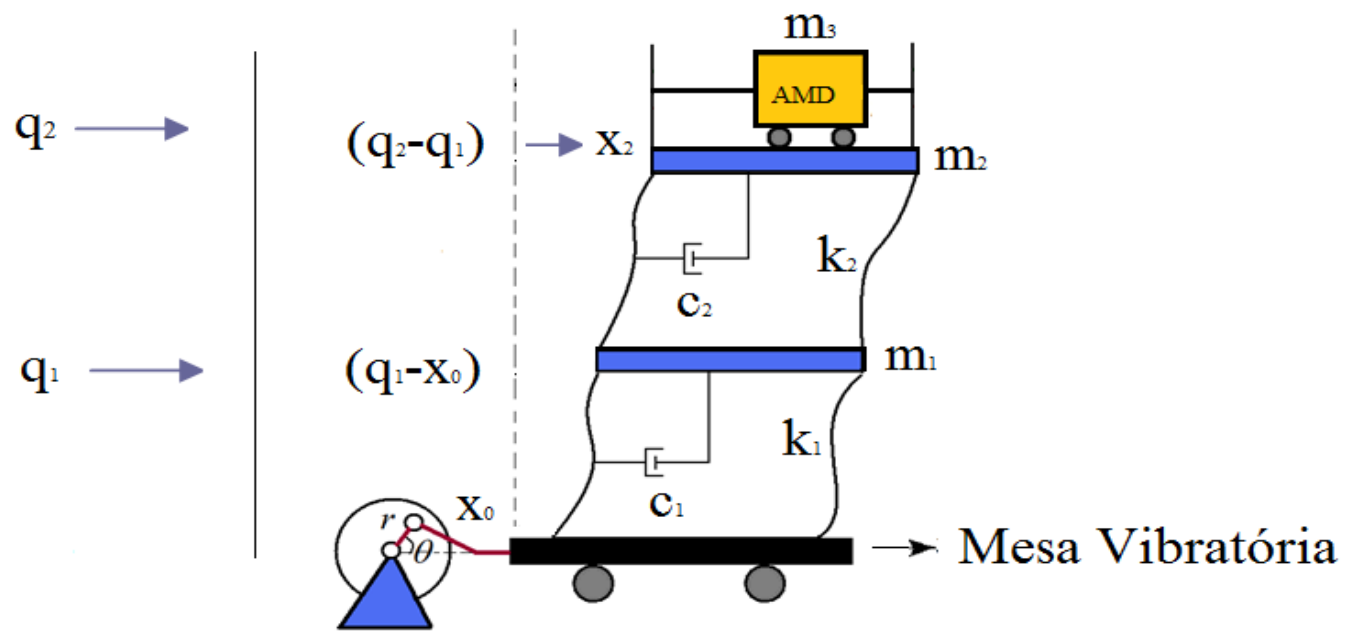

Figura 1: Estrutura de dois andares composta de um Amortecedor de Massa Ativa em seu topo.

Observação: AMD- Amortecedor de Massa Ativa; $m_{1}=$ massa do primeiro andar, $m_{2}=$ massa do segundo andar, $m_{3}=$ massa referente ao amortecedor, $k_{1}=$ rigidez primeiro andar, $k_{2}=$ rigidez segundo andar.

As equações de movimento do sistema da Fig. 1 são determinadas através das fórmulas de Lagrange, como são demonstradas abaixo.

$$
\ddot{q}_{1}=\left(\frac{k_{1}-k_{2}}{m_{1}}\right) q_{1}+\left(\frac{k_{2}}{m_{1}}\right) q_{2}-\left(\frac{k_{1}}{m_{1}}\right) x_{0}-\left(\frac{d}{m_{1}}\right) \dot{q}_{1}
$$

Onde a Eq. (1) demonstra a aceleração evidenciada no primeiro piso da estrutura, onde notase a presenta da primeira massa em todos componentes desta relação. Já a exemplificação da aceleração do segundo piso, Eq. (2), evidencia a presença das duas constantes de massa, tanto do primeiro andar da estrutura quanto a do amortecedor-AMD.

$$
\ddot{q}_{2}=-\left(\frac{k_{2}}{m_{2}}\right) q_{1}+\left(\frac{k_{2}}{m_{2}}\right) q_{2}+\left(\frac{d}{m_{2}}\right) \dot{q}_{2}-\left(\frac{e}{m_{3}}\right) \dot{x}_{2}
$$

A formulação principal, esta em torno da equação, a seguir, da qual exemplifica a aceleração decorrente do Amortecedor de Massa Ativa (AMD), como pode ser destacado pelos componentes que compõem tal ação, onde ambos estão contidos em tal sistema.

$$
\ddot{x}_{2}=\left(\frac{k_{2}}{m_{2}}\right) q_{1}-\left(\frac{k_{2}}{m_{2}}\right) q_{2}+\left(\frac{d}{m_{2}}\right) \dot{q}_{2}-\left(\frac{m_{2}+m_{3}}{m_{2} m_{3}}\right) e \dot{x}_{2}
$$

Assim através de tais formulações se conclui quais, são de fato, os parâmetros e constantes que interferem no deslocamento e aceleração de tal estrutura. Trazendo, consequentemente, a reflexão em torno dos sistemas de controle, que se verificam benéficos para a minimização de efeitos atuantes sobre a estrutura.

Com o objetivo de efetuar o levantamento bibliográfico, de revisões, das quais obtenham como tema principal os sistemas de controle passivos, ativos e semiativos. Abordando em destaque os Amortecedor de Massa Sintonizada e Amortecedor de Massa Ativa. Fez-se o estudo e a analise de uma estrutura de dois andares, quando a mesma é composta de um Amortecedor de Massa Ativa em seu topo.

Através deste contraponto, se verificou as equações que comprovam o movimento de tal estrutura, que de forma simples, exemplificam o movimento exercido pela mesma, durante a excitação de sua base. Ademais, analisa-se a funcionalidade de tal dispositivo e se investiga quais os pontos positivos e negativos de sua aplicação. Sendo assim, este trabalho comprova 
que de fato é possível aplicar tais sistemas a estruturas, para que estas tenham seus efeitos minimizados e consequentemente permita a atuação de tais dispositivos em estruturas.

Palavras-chave: Amortecedor de Massa Sintonizada, Amortecedor de Massa Ativa, Controle de Vibrações em Estruturas, Equações Diferenciais

\section{Referências}

[1] H. F. Silva, "Análise do Comportamento Dinâmico Não-Linear de Estruturas Sob Excitação de Suportes Não-Ideal” (ed. rev.- Brasil, São Paulo), 213p.

[2] J.L.P. Felix, “Teoria de Sistemas Vibratórios Aporticados Não-lineares e Não-Ideais”, Tese de Doutorado, UNICAMP, 2002.

[3] F. V. Quintino, Controlo Activo de Vibrações em Edifícios. Dissertação apresentada na Faculdade de Ciências e Tecnologia da Universidade Nova de Lisboa para obtenção do grau de Mestre em Engenharia Civil na especialidade de Estruturas e Geotecnia, Portugal, Lisboa, $141 \mathrm{p}, 2012$.

[4] L. Zuluaga Gomes, "Controle de Vibrações em Edifícios Submetidos á Ação de Cargas Dinâmicas Utilizando Amortecedor de Massa Sintonizado na Forma de Pêndulo". Dissertação de Mestrado, Publicação E.DM-009/07, Departamento de Engenharia Civil e Ambiental, Universidade de Brasília, Brasília, DF, 86p, 2007. 